\title{
Tocar para Ser: a Ontopsicologia como fundamento da identidade da orquestra Jovem Recanto Maestro ${ }^{1}$
}

\author{
Michael Fragomeni Penna ${ }^{2}$
}

Annalisa Cangelosi ${ }^{3}$

\begin{abstract}
Resumo: O mundo passa por transformações cada vez mais rápidas e de maior impacto. A sociedade procura a todo o momento ferramentas que possibilite solucionar seus grandes problemas. Neste trabalho se busca um passo em direção a essa necessidade, analisando a música como ferramenta para resolver o grande problema do homem: ele mesmo. A seguir se apresenta a forma como a Orquestra Jovem Recanto Maestro se especifica e se distingue. Descreve-se a missão e os valores do projeto segundo a Ontopsicologia. Utilizou-se uma metodologia qualitativa e quantitativa para verificar se a percepção que as pessoas que compõem o contexto social da Orquestra Jovem Recanto Maestro é reversível à identidade do projeto. No final se chega a uma série de sugestões para o fortalecimento do projeto com base em sua identidade.
\end{abstract}

Palavras-chave: Ontopsicologia; Orquestra Jovem Recanto Maestro; Tocar para Ser.

Play To Be: Ontopsychology As The Foundation Of The Identity Of The Recanto Maestro Youth Orchestra

Abstract: The world is undergoing ever faster and more impactful transformations. Society is always looking for tools to solve its big problems. In this work, a step towards this need is sought, analyzing music as a tool to solve the great problem of the human being: him/herself. The following is how the

\footnotetext{
${ }^{1}$ Síntese do Trabalho de Conclusão do Curso de Bacharelado em Ontopsicologia da Antonio Meneghetti Faculdade (Primeira Turma).

${ }^{2}$ Mestrando em Educação pela Universidade Federal de Santa Maria (UFSM). Bacharel em Ontopsicologia da Antonio Meneghetti Faculdade (AMF). Coordenador Pedagógico da Fundação Antonio Meneghetti. Coordenador da Orquestra Jovem Recanto Maestro.

${ }^{3}$ Doutora em Pedagogia Experimental pela Universidade La Sapienza de Roma (Itália), Especialista em Psicologia com abordagem em Ontopsicologia pela Universidade Estatal de São Petersburgo (Rússia). Orientadora, Docente e Pesquisadora da Antonio Meneghetti Faculdade, AMF.
} 
Recanto Maestro Youth Orchestra specifies and distinguishes itself. The mission and values of the project are described according to Ontopsychology. A qualitative and quantitative methodology was used to verify whether the perception that the people who make up the social context of the Recanto Maestro Youth Orchestra is reversible to the project's identity. In the end, a series of suggestions is made for strengthening the project based on its identity.

Keywords: Ontopsychology; Play to Be; Recanto Maestro Youth Orchestra.

\section{Juega Para Ser: La Ontopsicología Como Fundamento De La Identidad De La Orquesta Juvenil Recanto Maestro}

Resumen: El mundo está experimentando transformaciones cada vez más rápidas e impactantes. La sociedad siempre busca herramientas para solucionar sus grandes problemas. En este trabajo se busca dar un paso hacia esta necesidad, analizando la música como herramienta para resolver el gran problema del ser humano: él mismo. A continuación se detalla y se distingue la Orquesta Juvenil Recanto Maestro. La misión y los valores del proyecto se describen de acuerdo con la Ontopsicología. Se utilizó una metodología cualitativa y cuantitativa para verificar si la percepción de que las personas que conforman el contexto social de la Orquesta Juvenil Recanto Maestro es reversible a la identidad del proyecto. Al final, se hacen una serie de sugerencias para fortalecer el proyecto desde su identidad.

Palabras clave: Ontopsicología; Jugar para ser; Orquesta Juvenil Recanto Maestro.

\section{Introdução}

Antonio Meneghetti ensinou em toda sua vida a transcendência da arte na formação de atitudes e condutas vencedoras para que o ser humano possa realizar seu projeto de natureza. Conforme ele, a arte deveria ser vista como expressão do belo e como função para o desenvolvimento do ser humano. Cada pessoa realiza todos os dias as escolhas que geram os resultados da sua vida. Quando o resultado é em benefício do projeto de natureza da pessoa, ela concretizou uma ação vencedora. Por projeto de natureza se entende as características inatas do ser humano que o definem, que lhe dão identidade e que, se descobertas, fortalecidas e atuadas, fazem da pessoa um ser realizado. A música foi utilizada ao longo da história, por diversas instituições, tanto na formação técnica de excelentes músicos, como no resgate social. Além disso, a funcionalidade da música pode ser ampliada para a formação do ser humano. A Orquestra Jovem Recanto Maestro traz, por sua vez, a 
novidade da Ontopsicologia que, com seus conceitos, instrumentos e aplicações, serve como base para pensar, tanto a identidade como a metodologia da Orquestra. Centenas de crianças e jovens podem ser ajudadas a descobrirem seu potencial e desenvolvê-lo através de um instrumento musical e da prática orquestral.

Este trabalho se justifica pela necessidade de que se discuta como a música pode ser funcional para o desenvolvimento do ser humano, para que cada vez mais o contato com essa possa adquirir um significado de formação e estilo de vida. Sendo a arte a expressão do belo, sua transcendência é gerar beleza em todos aqueles que se envolvem de diferentes modos com ela. Observa-se que o estudante e o profissional da música estão muito preocupados em adquirir capacidades técnicas ou formalizar trabalhos que possibilitem um aprofundamento teórico para melhor execução musical. A técnica tem fundamental importância para o ser humano exercer qualquer atividade. Apesar disso, se faz necessário que todo aquele que atue na música - seja executante, seja professor, estudante ou empresário - reflita sobre um papel mais além da técnica. Uma execução musical não poderia ser somente uma distração para o público, ou uma aula não deveria ser tomada apenas para correção de erros técnicos. Qual o real valor de um concerto, de aprender um instrumento musical? A função que estas experiências artísticas cumprem na sociedade como ferramenta de formação, instrumento de intervenção, deve ser estudada cada vez mais para que se aprofunde no real valor da música.

A percepção dos diferentes grupos que compõem o contexto social da Orquestra Jovem Recanto Maestro tem correlação com a identidade da mesma? Esse é o problema de pesquisa que esse trabalho tem por objetivo geral responder. Já como objetivos específicos se busca apresentar quais as especificidades que definem a identidade da Orquestra Jovem Recanto Maestro, assim como, descrever a missão e os valores da Orquestra Jovem Recanto Maestro em relação à Ontopsicologia. Também se procura discorrer sobre a pedagogia ontopsicológica e OntoArte como aplicações da Ontopsicologia e compreender como são praticadas junto ao projeto Orquestra Jovem Recanto Maestro. Ainda, pretende-se colher manifestações de alunos, responsáveis, staff, diretoria, parceiros e público, acerca das próprias percepções sobre o trabalho realizado pela Orquestra Jovem Recanto Maestro. Ao final do trabalho se pretende contribuir com recomendações para fortalecer as ações do projeto com base em sua identidade. 


\section{Fundamentação Teórica}

Nas linhas abaixo se mostra, por um lado, o que é a Ontopsicologia e algumas das suas aplicações (OntoArte, Pedagogia). Sucessivamente, os caminhos da Ontopsicologia e da música se encontram no tópico que fala sobre a Orquestra Jovem Recanto Maestro, sua missão e valores.

\subsection{Ontopsicologia}

Ao longo de muitos séculos o conhecimento se desenvolve em todas as culturas levando a humanidade a um aprimoramento técnico e intelectual. Parmênides ${ }^{4}$ é um dos primeiros filósofos a ter a compreensão de que cada pessoa tem dentro de si mesmo a verdade sobre si e sobre aquilo que o rodeia. Um século depois, Aristóteles ${ }^{5}$ vai além ao entender que o corpo e a alma estão em "estreitíssima ligação" ao definir "a alma como forma e ato de um corpo vivente e dotado de órgãos" (CAROTENUTO, 2009, p. 22, grifo do autor).

Nos séculos XV e XVI os pensadores da época se dão conta da necessidade de voltar ao conhecimento grego como forma de contribuir para o desenvolvimento da sociedade europeia que havia passado pela Idade Média por mil anos entre os séculos $\mathrm{V}$ e XV. Quinhentos anos depois da retomada realizada pelos Humanistas, o filósofo e matemático Edmund Husser ${ }^{6}$ propõe, em 1935, um novo resgate dos princípios gregos ao expor a crise das ciências europeias em suas conferências nas cidades de Praga e Viena. Em paralelo ao

\footnotetext{
${ }^{4}$ 515-440 a.C.

${ }^{5}$ 384-322 a.C.

${ }^{6} 1859-1938$.
} 
desenvolvimento técnico, o homem não desenvolveu a si mesmo como humano, no entanto se desresponsabilizou de tal trabalho atribuindo à "ciência" como objeto externo o que lhe cabia como ente, como ser. Desse modo todas aquelas ciências e métodos estavam por construir uma realidade alheia ao humano em si, sem um sentido real, ontológico.

Antonio Meneghetti ${ }^{7}$ adotou a palavra Ontopsicologia como definição para o "estudo dos comportamentos psíquicos em primeira causalidade, incluída a compreensão do ser" (2014, p. 11). O critério da ciência ontopsicológica é o Em Si ôntico "segundo as 15 fenomenologias ${ }^{8}$ homologadas em situação histórica, entre as quais presentes ao menos: 1) identidade (ISO), 2) utilitarismo, 3) funcionalidade" (MENEGHETTI, 2010, p. 136). Quer dizer que os resultados das ações do homem devem ser útil e funcional à identidade do seu projeto de natureza.

Para vivermos a realização da vida devemos encontrar esse critério, nossa identidade, aquilo que nos é próprio, o que é de natureza. Cada pessoa tem sua identidade, sua natureza, sua realidade, assim como uma árvore que possui suas características próprias de acordo à função que ela exerce naquele meio. Também a pessoa tem essa realidade, que é como uma semente. Como se diz por aí: "uma semente de laranja não pode dar maçã”. O ser humano tem o Em Si ôntico que é a semente onde todas as propriedades, características da realidade da pessoa estão contidas. A ciência ontopsicológica busca isolar e desenvolver plenamente essa natureza para que cada pessoa chegue à sua realização e seja função para si e para os demais. Quer dizer que cada ser humano possa desenvolver em ação todo seu potencial e, ao realizar seu projeto, também se soma a outras pessoas que igualmente desenvolvem seu projeto de natureza. Dessa maneira, através da ação, a pessoa se torna líder, contribuindo para o desenvolvimento daquele ambiente.

\footnotetext{
7 1936-2013.

${ }^{8}$ Sobre as 15 fenomenologias ou características do Em Si ôntico, cfr. Meneghetti, 2010, p. 159.
} 


\subsection{OntoArte}

Dentre as aplicações da Ontopsicologia encontramos a OntoArte. Ao explicar como pinta, Meneghetti fala a respeito da "dinâmica da emoção" (2018, p. 117). Explica que, quando faz os quadros, sempre busca colocar a si mesmo, o ser, na emoção, ou seja, no "êxtase da ação". Esse posicionamento permite que daquela ação se produza vida, beleza, sendo assim, “Arte, Arte do fazer, Arte do viver, Arte do ser”. Dessa maneira a dinâmica da emoção é um “viver para realizar” (2018, p. 119).

Pode-se trazer outro exemplo, dessa vez da música. Sergiu Celibidache ${ }^{9}$ explica que a música é um movimento, parte de um ponto para expandir gerando tensões e distensões. Com a evolução dessa expansão se chega a um clímax e retorna ao ponto de partida. Conclui que o objetivo não é seguir o movimento das notas, a parte material, mas sim o movimento da consciência humana (ROCA, 2017, p. 100). O único objetivo de um concerto, para Celibidache, é que o público compartilhe da "mesma experiência, da mesma verdade", seja capaz de levar sua consciência "pelo mesmo caminho que recorreu a consciência de Celibidache" (ROCA, 2017, p. 59).

O fazer artístico, a música nesse caso, não pode ser somente uma técnica para tocar um instrumento. Para a música acontecer deve haver a revelação do ser por parte do artista para que o mesmo seja um "formalizador do imaginário" de uma criação funcional à vida (MENEGHETTI, 2018, p. 114). Isso significa que a música deve existir para gerar vida naquele que toca, como na pessoa que faz a fruição. A técnica deve ser um meio para chegar ao fim que é o contato, o tocar do sujeito com o objeto, do artista com o fruidor.

\subsection{Pedagogia Ontopsicológica}

Outra das aplicações da ciência ontopsicológica é a pedagogia. Para Meneghetti, por a relação com o ser, “a música é pedagogia: o espírito é pedagogia a uma progressiva civilização, a valores mais funcionais e afinados" (2003, p. 299). Para ensinar a maneira para que uma pessoa alcance seu pleno desenvolvimento, se faz necessário uma pedagogia que é

\footnotetext{
9 1912-1996.
} 
definida por Meneghetti como "a arte de como coadjuvar ou evolver uma criança à realização" (2014, p. 14). Para levar o indivíduo à realização é necessária uma pedagogia que tenha a capacidade de individuar o potencial daquela pessoa e desenvolvê-lo de acordo à sua identidade.

Observa-se a necessidade de um método que possa identificar a função da pessoa no contexto social e desenvolver ao máximo seu potencial de maneira que condiga com a natureza de cada uma. Meneghetti escreve sobre a importância de "educar o sujeito a fazer e a saber a si mesmo: fazer uma pedagogia de si mesmo como pessoa líder no mundo, educar um Eu lógico histórico ${ }^{10}$ com capacidades e condutas vencedoras" (2014, p. 14). Com essa definição encontramos uma pista de que, nesse processo, é necessária uma responsabilização para haver uma ação e uma transformação.

A pedagogia ontopsicológica traz as descobertas da Ontopsicologia para a formação de protagonistas no mundo. Ensina que os verdadeiros valores humanos se encontram no próprio homem e que a sociedade deve ser aceita e seguida como regra externa, mas não tomada como verdade interna. Não devemos seguir acreditando que a sociedade, a cultura, o governo são o critério de natureza do homem. Deve haver uma responsabilização de que somos os únicos responsáveis por onde nos encontramos. É cada ser humano aquele que escolhe a cada momento o resultado da sua vida. As frustrações, tristezas, angústias, incertezas, dores, são fruto de escolhas que fizemos ao longo da vida. Escolhas que foram feitas baseadas em critérios convencionais, em estereótipos sociais e não em um critério verdadeiro, de natureza, o Em Si ôntico.

\subsection{Orquestra Jovem Recanto Maestro}

Promovida pela Fundação Antonio Meneghetti e executada pela Associação OntoArte, a Orquestra Jovem Recanto Maestro foi constituída em 2015 alcançando alunos da rede pública de ensino da Quarta Colônia de Imigração do Rio Grande do Sul por meio do ensino da música. Cláudio Carrara, diretor geral do projeto, explica que a Orquestra "nasceu a partir de uma provocação do Professor Meneghetti que dizia que o brasileiro não

\footnotetext{
10 “O Eu que, de fato, escolhe e define seja em positivo, seja em negativo” (MENEGHETTI, 2012, p. 103).
} 
tinha temperamento para a música porque ao primeiro elogio ele já se acomoda" (2017). Em todo projeto são oferecidas aulas de violino, viola, violoncelo, contrabaixo, flauta, clarinete, oboé, fagote, trompete, trompa, trombone, tuba, bombardino, percussão e coral nos municípios de Agudo, Faxinal do Soturno, Restinga Sêca, Santa Maria, São João do Polêsine, Silveira Martins. O Maestro Antonio Carlos Borges-Cunha, diretor pedagógico do projeto, explica que o que se está fazendo é "desenvolvendo uma pedagogia, desenvolvendo um método que proporcione prazer à criança. Eu acho que tudo o que nós queremos é alegria, é felicidade, é sentir-se capaz" (ASSOCIAÇÃO BRASILEIRA DE ONTOPSICOLOGIA, 2015 , p. 30).

A Orquestra Jovem Recanto Maestro surge como ferramenta de uma das aplicações da Ontopsicologia que é a OntoArte. Ergue-se da tese de Meneghetti de que não se deve fazer arte somente por fazer, "mas para que exista valor, deve existir a busca de um crescimento, de uma evolução para algo que faça a existência mais próxima às proporções do ser" (2003, p. 57). Quer dizer que a arte, segundo Meneghetti, é um "ser para a vida", "uma capacidade de evolução criativa, realização" (2003, p. 55). A partir das premissas dadas pela Ontopsicologia e da aplicação da OntoArte surge a missão da Orquestra: Tocar para Ser.

\subsubsection{Tocar para Ser}

Para Carrara, independentemente de qualquer nota que for tocada, deve "acontecer a música" (2017). Independentemente de ser uma criança ou um profissional tocando, deve existir algo verdadeiro, algo que expresse a essência da alma, o belo da espirito e que comova o público. Segundo Carrara "a música não é nota, a música não está na partitura, a música está na atitude da relação do músico com o público" (2017). Para o diretor geral do projeto, a missão significa "tocar no sentido de não só tocar o instrumento, mas de mover o músico, mover o público em algo que tivesse acontecendo naquela experiência artística musical. Fazer nascer através da música a manifestação do belo que somos" (CARRARA, 2017). Para Celibidache "a música pode transmitir sua singularidade, sua unicidade e não existe nada mais belo que isso" (1992, tradução nossa). 
Também a partir das premissas dadas pela Ontopsicologia e da aplicação da OntoArte se formaliza os valores da Orquestra Jovem Recanto Maestro: Excelência, Protagonismo Responsável e Estética como Ética.

\subsubsection{Excelência}

Meneghetti fala que a arte "é o que estrutura a presença do espírito, da vis, da vida, algo que já é, mas que deve ainda acontecer materialmente” (2010, p. 213). É indispensável a técnica para alcançar a arte superior. "Técnica é o modo como traduzir em função externa uma intuição apriórica" (MENEGHETTI, 2003, p. 213). Para se chegar à arte superior é necessário a passagem técnica. Saber fazer bem alguma coisa é fundamental. Para tal, Meneghetti coloca que é necessário "cultura, preparação, experiência e sempre constante disponibilidade a aprender" (2017, p. 95). A excelência é uma atitude perante a vida, de persistir, treinar e sempre realizar as próprias ambições da melhor forma possível. Celibidache entende que o ensaio de uma orquestra não é para fazer música, mas para se dizer inúmeros "nãos". "Não tão rápido", "não tão forte". "Existem milhões de "nãos', mas somente um "sim"” (1992, tradução nossa). Esse "sim" que Celibidache fala nada mais é quando a música acontece, quando a vibração das notas leva a informação do ser. Para isso são necessários muitos "nãos" porque a busca da excelência é um processo de aprendizado, contra hábitos, vontade, disciplina, isto é, muito trabalho.

Ao longo da história ${ }^{11}$ os diversos movimentos artísticos pedagógicos se utilizaram da excelência musical para formar cidadãos, para o resgate social, para a liturgia. A

\footnotetext{
${ }^{11}$ Inicia-se este breve resgate histórico a partir dos gregos, que viam a música como ferramenta para resolver alguns problemas sociais através da aplicação na formação do ser humano (FONTERRADA, 2008, p. 26), passando pelas scholae cantori medievais que eram focadas na "boa produção musical, destinada a atender às necessidades litúrgicas das igrejas, conventos ou paróquias (FONTERRADA, 2008, p. 36), chegando no período do renascimento italiano. Seguindo "a tendência da época e a visão de mundo da sociedade, que reconhecia sua responsabilidade na formação de seres humanos" (FONTERRADA, 2008, p. 48), surge a música como ferramenta para ser aplicada nas casas de órfãos italianas e onde se formou uma série de exímios músicos. No século XIX, com as bases de liberdade, igualdade e fraternidade e com a praticidade, mecanicidade e produção em série exigida pela revolução industrial, o ensino da música assume outro papel. Através do Conservatório Superior de Paris se testemunha uma mudança nos rumos pedagógicos artísticos e de financiamento da instituição que ensina música (GOMES, 2002, p. 64). Nos anos 70 surge uma outra forma de ver a música como instrumento para atuar na sociedade. Com o objetivo de que a educação musical se modernize (EL SISTEMA, 2016, tradução nossa) desabrocha na Venezuela um novo modelo pedagógico, que ao longo das últimas décadas vem se espalhando pelo mundo por meio de diversas instituições inspiradas no modelo venezuelano.
} 
Orquestra Jovem Recanto Maestro, fundamentada na Ontopsicologia, propõe um passo além: a excelência técnica é usada como ferramenta para que a criança e o jovem conheçam seu potencial e possam atingir a própria realização.

\subsubsection{Protagonismo Responsável}

Meneghetti estabeleceu a visão da ciência ontopsicológica como sendo "o homem protagonista responsável, baseado em uma virtualidade capaz de atuação pessoal no ser" (2010, p. 130). Primeiro cada indivíduo tem o dever para consigo mesmo, com a própria vida, na construção de si mesmo como pessoa de valor. A Fundação Antonio Meneghetti entende que protagonista responsável é "aquele que sabe, na relação humana, estabelecer a ordem de funções para cultivar o crescimento das pessoas sem impedir a autonomia pessoal" (2016, p. 22).

Quando Carrara (2017) fala sobre o referente valor da Orquestra, ele explica que a gratificação deve ser sobre o resultado da evolução e dessa forma se dá sempre a motivação correta para a criança. Não se deve cair no erro da gratificação sem mérito. A criança deve ter por motivação a busca pelo resultado, sempre poder melhorar. Entende-se, dessa maneira, que a música deve ser usada como ferramenta para o desenvolvimento da responsabilidade. Quando o aluno recebe um aplauso de uma plateia entusiasmada, ele deve entender que fez um trabalho bem feito. Só que esse protagonismo está relacionado a uma responsabilidade que o aluno deve ter com sua autonomia, crescimento e com as pessoas que estão com ele.

\subsubsection{Estética como Ética}

A palavra "estética" designa "a ciência da arte e do belo" (ABBAGNANO, 2007, p. 367). Meneghetti explica que o belo é a harmonia de várias proporções e que "faz estética" (2012, p. 33). Portanto Meneghetti define a estética como sendo "a percepção externa do proporcional em ato" (2012, p. 100). Já a ética (do grego "ethos" = modo de viver) Meneghetti define como "o modo em que se usa o fato vida" (2003, p. 67).

A Estética como Ética está ligada com a ideia de que todas as ações devem ter como propósito a visão do belo alcançada por meio de uma conduta ética, de responsabilidade e estudo. Para se ter uma atitude estética é necessário uma "capacidade de pensar com ordem, ter critérios exatos na mente" (MENEGHETTI, 2003, p. 237). 
Carrara (2017) explica que as crianças desenvolvem na Orquestra Jovem Recanto Maestro uma capacidade estética que é útil para usar posteriormente no dia-a-dia em qualquer atividade. Isso acontece quando deixam de ouvir qualquer música e começam a ouvir boa música, acostumando o ouvido a isso. Dessa maneira, a Estética como Ética é a conduta fundada no Em Si ôntico, na proporção e na ordem: realizar escolhas de acordo com a própria identidade e em vantagem do próprio crescimento, segundo a situação do momento.

\section{Método}

No presente trabalho, realizou-se uma pesquisa empírica quali-quantitativa de caráter exploratório com o objetivo de verificar se a percepção que as pessoas que compõem o contexto social da Orquestra Jovem Recanto Maestro tem correlação com a identidade do projeto. Participam da pesquisa pessoas de todos os grupos envolvidos direta ou indiretamente no desenvolvimento do projeto. Separam-se esses grupos em: Diretoria; Amigo, Padrinho/Madrinha; Pai/Mãe ou Responsável; Público em Geral; Staff; Aluno.

No grupo Diretoria, pesquisou-se profissionais que fazem parte do comitê diretor da Orquestra, assim como lideranças que participam do conselho da Fundação Antonio Meneghetti que é a promotora do projeto. O grupo Staff é formado por professores, colaboradores administrativos e estagiários que realizam seus trabalhos no dia-a-dia do projeto. Já o grupo Amigo, Padrinho/Madrinha é formado por aquelas pessoas, físicas ou

jurídicas, que contribuem financeiramente para a manutenção da Orquestra. Esse grupo aporta de maneira espontânea, com uma cota mensal ou anual, e em troca recebe algumas contrapartidas de acordo com a categoria da contribuição. No grupo Público em Geral, estão aquelas pessoas que assistiram, ao menos uma vez, a algum concerto da Orquestra Jovem Recanto Maestro. O grupo Pai/Mãe ou Responsável é composto daqueles que se relacionam com o projeto através do acompanhamento de suas crianças e jovens nas aulas, concertos e estudos em casa. Por fim, no grupo Aluno se têm aquelas crianças e jovens que participam do projeto nas orquestras e nos corais. Buscaram-se pesquisar pessoas de diferentes faixas etárias, de cidades e perfis diferentes, obtendo uma mostra condizente com o contexto social da Orquestra. 
Para essa pesquisa se criaram dois instrumentos de coleta de dados. Um dele foi a entrevista, semi-estruturada, que foi aplicada para o grupo Diretoria, gravada em áudio e transcrita por um terceiro e revisadas pelo autor. Esse grupo é constituído pelas pessoas responsáveis em primeira pessoa pelo projeto. Sendo assim, havia interesse em coletar informações mais aprofundadas, que um questionário não iria permitir obter. Por essa razão se elegeu a construção de tal instrumento de acordo ao perfil diferenciado desse grupo. As perguntas foram realizadas pelo próprio autor e não foram informadas previamente para que as respostas fossem mais diretas. O outro instrumento é o questionário, também semiestruturado, que foi aplicado nos grupos denominados: Staff; Amigo, Padrinho/Madrinha; Público em Geral; Pai/Mãe ou Responsável; Aluno. Os questionários foram construídos de tal maneira que fossem preenchidos sem necessidade da pessoa se identificar para garantir a privacidade dos respondentes. Esses instrumentos foram construídos do zero, já que até hoje não existem pesquisas sobre a Orquestra Jovem Recanto Maestro.

A Orquestra possui diversos níveis de alunos, de diferentes idades, provenientes de várias cidades e que participam de diferentes grupos dentro do próprio projeto, assim como uma diretoria que provém de distintos locais. Dessa maneira, os questionários e as entrevistas foram aplicados em vários momentos, utilizando-se, quando necessário, da equipe de monitores e professores da própria Orquestra, mas sempre com a presença e supervisão do autor deste trabalho em cada coleta.

Após a coleta passou-se à análise dos dados. O procedimento utilizado neste trabalho é conhecido como mineração de dados. Gustavo Lovato explica que o objetivo da mineração é "identificar palavras, termos, expressões relevantes que se destacam no domínio minerado, encontrando padrões em dados não estruturados" (2015, p. 10). Lovato complementa ainda que, após a mineração dos dados, é necessário gerar estatísticas que devem ser visualizadas para melhor compreensão dos dados $(2015$, p. 10); nesse trabalho, utiliza-se principalmente da Nuvem de Palavras ${ }^{12}$ para tal. No processo, existem duas importantes etapas que são a

12 Amaral (2016) explica que as nuvens de palavras podem ser usadas em mineração de texto e também em análise de sentidos, indo muito além do que mero gráfico decorativo. "O gráfico é gerado a partir de uma lista de palavras com sua respectiva frequência. As palavras com maior frequência são desenhadas maiores. Outros elementos, como cores, fontes, proporção entre palavras horizontais e verticais podem ser definidas na geração do gráfico" (AMARAL, 2016, p. 70). 
extração e a mineração propriamente dita. A extração da informação é onde as palavras que não são relevantes são retiradas e a informação é estruturada. Já a mineração da informação é onde se aplica as "técnicas adequadas de análise para obter bons resultados" (STAUDT, 2016, p. 11).

No tópico seguinte estão apresentados e analisados os dados coletados.

\section{Discussões e Resultados}

Quando se pediu para que os diferentes grupos escrevessem cinco palavras que, de acordo ao seu entendimento, definiam o projeto Orquestra Jovem Recanto Maestro, obtevese os resultados apresentados nas próximas linhas. Observa-se que o grupo Público em Geral define a Orquestra, primeiro como cultura, e depois como responsabilidade e alegria. A cultura pode ser entendida como "a formação do homem, sua melhoria e seu refinamento", como também, "o conjunto dos modos de viver e de pensar cultivados, civilizados, polidos" (ABBAGNANO, 2007, p. 225). Esse grupo associa a Orquestra com a cultura, o que é comumente feito, já que se costuma relacionar o ir a um concerto, tocar um instrumento musical como cultivo, refino, melhora do homem.

A segunda palavra conectada pelo Público em Geral com o projeto foi responsabilidade, a qual deriva do latim respondere, que significa responder. Para Meneghetti "a responsabilidade nasce de um determinismo derivante do indivíduo situado em ambiente" (2010, p. 415). É aí que se forja a moral do humano para possibilitar a realização e é a base da pedagogia ontopsicológica citada acima como uma aplicação da Ontopsicologia. Dessa maneira a responsabilidade se encontra como um dos valores da Orquestra. A palavra alegria aparece logo depois: o Em Si ôntico, que é o critério pelo qual - por natureza - devemos atuar, é percebido segundo 15 fenomenologias e, dentre elas, a alegria.

No grupo Amigo, padrinho/madrinha se observa uma percepção, quanto à definição do projeto, muito parecida com a do Público em Geral. A primeira palavra citada pelo grupo é responsabilidade. Logo em seguida aparecem as palavras alegria e formação. Por outro lado, para o grupo Pai/Mãe ou Responsável a Orquestra está relacionada primeiramente como aprendizado e depois como educação. Para Abbagnano, aprendizado é a "aquisição 
de uma técnica qualquer, simbólica, emotiva ou de comportamento" (2007, p. 75). Nesse grupo parece que não seja tão claro o diferencial que a identidade da Orquestra aporta para suas crianças e jovens.

O grupo Aluno cita em primeiro lugar a palavra legal e em terceiro a palavra bom, que mostram o gosto que o grupo tem pela Orquestra. Em segundo lugar, surge o termo aprender que já apareceu, também, na percepção de outros grupos. Já para o grupo Staff a palavra em destaque é colega, seguido por excelência e futuro. A excelência é um dos valores do projeto e é importante também para esse grupo de colaboradores. Quando Meneghetti fala sobre saber fazer bem alguma coisa, explica que o jovem que quer fazer carreira e obter reconhecimento econômico deve ir "com a oferta generosa de si mesmo e capacidade específica de serviço" (2017, p. 95).

Figura 1 - Nuvem de palavras com a definição da Orquestra Jovem Recanto Maestro pelos grupos: público em geral; amigo, padrinho/madrinha; pai/mãe ou responsável; aluno; staff.

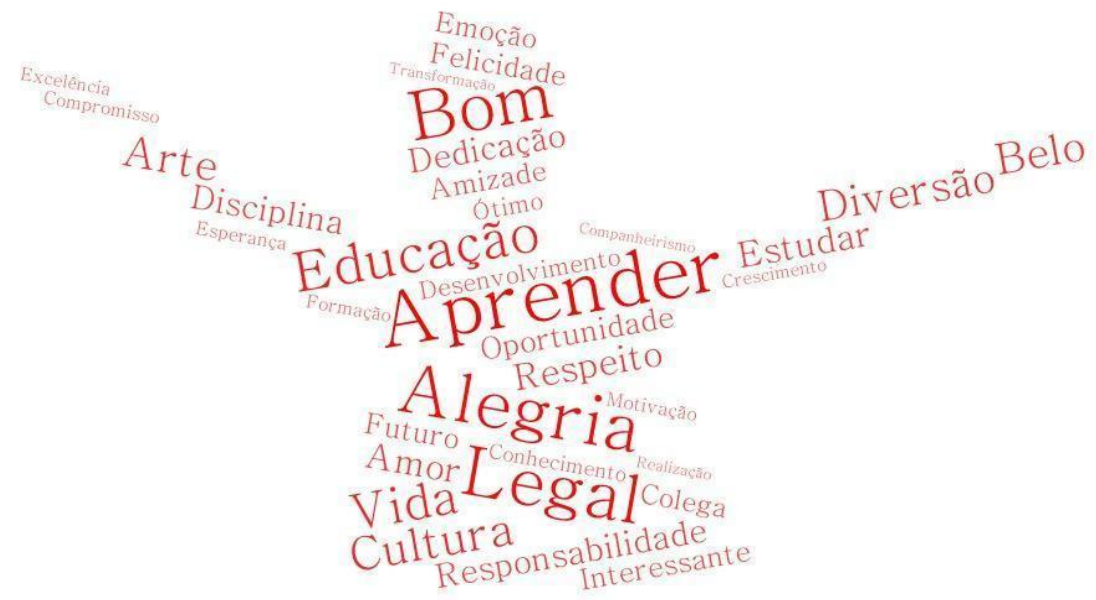

Fonte: Elaborado pelo autor, 2019.

Na Figura 1 é apresentado um gráfico em forma de nuvem de palavras que representa a definição geral de todos os grupos com relação à Orquestra. O gráfico da Figura 1 é construído a partir dos termos expressos pelos participantes, detalhados no Quadro 1, quando perguntados sobre como definiriam, através de palavras, o projeto da Orquestra Jovem Recanto Maestro.

De modo geral, a correlação entre a definição que os grupos que compõe o contexto social da Orquestra Jovem Recanto Maestro tem e a identidade do projeto é verificável em 
alguns pontos. Primeiro, que é muito presente a relação do projeto com o aprendizado. A principal percepção é de que na Orquestra se aprende a técnica de um instrumento. Poderia ser um resultado normal para um projeto que ensina música, mas com o entendimento da missão e valores do projeto se observa que essa percepção indica que ainda falta entendimento sobre o objetivo da Orquestra, da excelência técnica ser um meio e não um fim no aprendizado musical.

Quadro 1 - Definição geral do projeto Orquestra Jovem Recanto Maestro pelos grupos: público em geral; amigo, padrinho/madrinha; pai/mãe ou responsável; aluno; staff.

\begin{tabular}{|c|c|c|c|c|c|}
\hline Palavra & quant. & Palavra & quant. & Palavra & quant. \\
\hline aprender & 97 & desenvolvimento & 19 & Crescimento & 9 \\
\hline legal & 73 & felicidade & 19 & $\overline{\text { Colega }}$ & 7 \\
\hline alegria & 54 & dedicação & 17 & Compromisso & 7 \\
\hline educação & 51 & estudar & 17 & Esperança & 7 \\
\hline responsabilidade & 51 & amizade & 14 & Motivação & 7 \\
\hline bom & 44 & Arte & 14 & Ótimo & 7 \\
\hline diversão & 41 & Vida & 13 & Companheirismo & 5 \\
\hline oportunidade & 31 & emoção & 12 & Transformação & 5 \\
\hline cultura & 26 & futuro & 12 & Excelência & 3 \\
\hline respeito & 24 & conhecimento & 10 & Formação & 3 \\
\hline disciplina & 21 & Amor & 9 & Realização & 2 \\
\hline interessante & 20 & Belo & 9 & & \\
\hline
\end{tabular}

Fonte: Elaborado pelo autor, 2019.

A palavra legal é um indicativo da satisfação que se tem, que também é expressa com a palavra alegria. Tal palavra é um dos fenômenos através do qual podemos evidenciar o critério da Ontopsicologia, o Em Si ôntico. Já com a palavra responsabilidade é possível observar que existe a associação da definição da Orquestra com a pedagogia ontopsicológica, o que é um indicativo da parte que é mais trabalhada no projeto e que é reversível com os propósitos do mesmo. 
A próxima pergunta era para que os pesquisados pudessem escrever frases, de acordo ao seu entendimento, sobre o porquê da existência da Orquestra Jovem Recanto Maestro. A palavra que mais ocorre no grupo Aluno é aprender e a segunda, ensinar. Observa-se o entendimento do aluno de que a Orquestra existe para um aprendizado técnico. Interessante é a terceira palavra: Vida. Pode-se entender a vida como "o lugar da força", aquilo que se move por si só a um "intrínseco fim no particular e no total” (MENEGHETTI, 2012, p. 269). Parece que existe uma pequena percepção da relação desse aprendizado com a vida de cada um, mas que não é bem entendida ou constatada. Um aluno expressa que a Orquestra existe para "ajudar no desenvolvimento das novas gerações", enquanto um outro resume o entendimento de muitos ao explicar que a Orquestra existe para "aprendermos a ser uma pessoa melhor".

As primeiras palavras que aparecem nas respostas do grupo Pai/Mãe ou Responsável são aprender e desenvolver. Um participante expõe que a Orquestra existe "para resgatar valores que o mundo está perdendo". Outro participante escreve que "é uma oportunidade de um futuro melhor para minha filha”. Esse grupo observa na Orquestra uma oportunidade para o desenvolvimento do aluno, mas não se tem uma correlação muito clara com a identidade da mesma.

O grupo Amigo, Padrinho/Madrinha também expõe sobre seu entendimento do porquê da existência do projeto. Na fundamentação teórica desse trabalho, desenvolveu-se sobre a Ontopsicologia e suas aplicações na OntoArte e na pedagogia ontopsicológica. A palavra humanismo, citada por esse grupo, não somente se refere a um humanismo histórico, desenvolvido na Itália dos séculos XIV e XV, mas a um humanismo perene ensinado através da Ontopsicologia. Um respondente resume os resultados ao expressar que a Orquestra Jovem Recanto Maestro "é uma nova proposta de ensino da música na qual se tenta encontrar e reforçar a unicidade de cada aluno, ao mesmo tempo responsabilizando-o no seu processo de crescimento pessoal e profissional".

Diferente dos demais grupos, o Staff não concentrou suas ocorrências de palavras em algumas específicas, mas distribuiu seu entendimento em várias. Para entender um pouco mais podemos analisar o seguinte comentário sobre a existência da Orquestra: "Para criar uma nova e avançada cultura musical e a partir disso trabalhar na criança uma nova forma 
de ver as coisas". Por sua vez, o grupo Público em Geral cita mais vezes a palavra desenvolvimento, seguida por oportunidade e valor. Esse grupo percebe que a Orquestra é uma proposta de valor para o desenvolvimento dos participantes, como se nota em uma das respostas dos questionários, na qual fala-se que o projeto existe "como oportunidade para cada pessoa conhecer e exercer valores e encantamento pela música". Também pode-se trazer a frase de outro respondente, para dizer que o projeto existe "pela formação juvenil em inteligência e ação harmônica e bela".

Na nuvem de palavras da Figura 2, pode-se observar a visão geral do entendimento dos diferentes grupos estudados sobre o porquê da existência do projeto Orquestra Jovem Recanto Maestro. No Quadro 2, pode ser observado numericamente o que é expresso na Figura 2.

Figura 2 - Nuvem de palavras do porquê da existência da Orquestra Jovem Recanto Maestro pelos grupos: público em geral; amigo, padrinho/madrinha; pai/mãe ou responsável; aluno; staff.

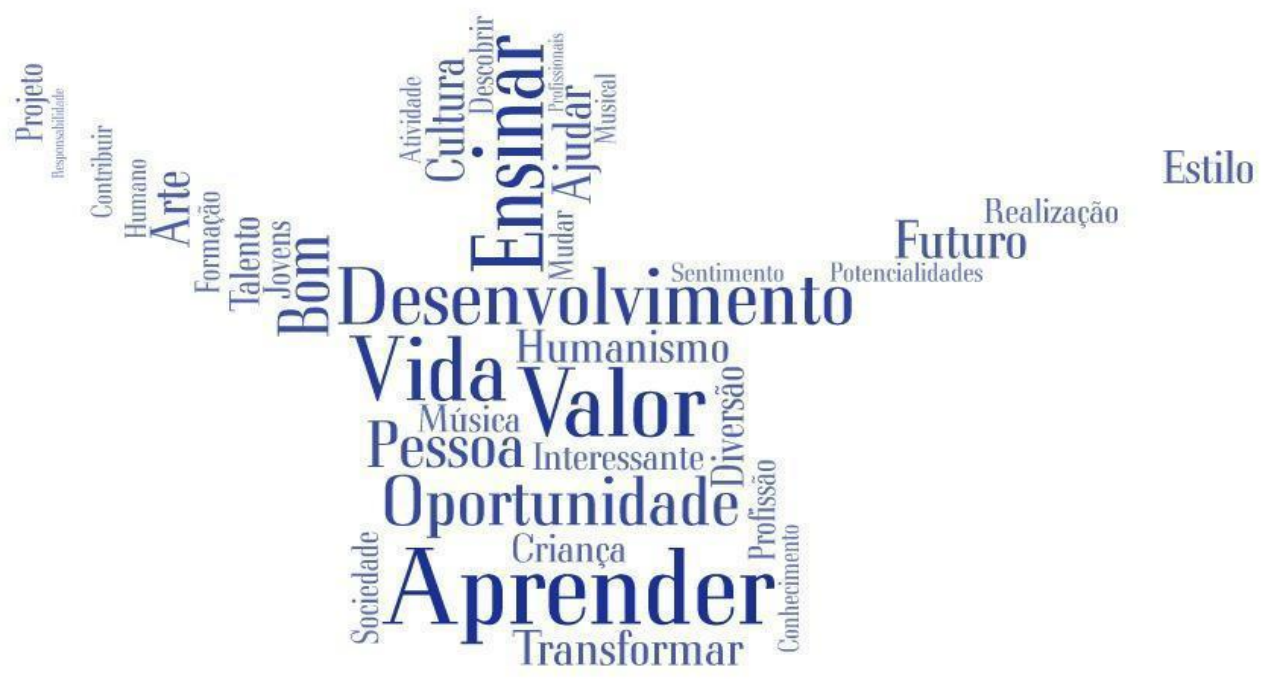

Fonte: Elaborado pelo autor, 2019.

Quadro 2 - Visão geral do porquê da existência do projeto Orquestra Jovem Recanto Maestro pelos grupos: público em geral; amigo, padrinho/madrinha; pai/mãe ou responsável; aluno; staff.

\begin{tabular}{|l|c|l|c|l|c|}
\hline \multicolumn{1}{|c|}{ Palavra } & quant. & \multicolumn{1}{|c|}{ Palavra } & quant. & Palavra & quant. \\
\hline aprender & 68 & formação & 7 & profissão & 4 \\
\hline desenvolvimento & 54 & Futuro & 7 & sentimento & 4 \\
\hline
\end{tabular}




\begin{tabular}{|l|c|l|c|l|c|}
\hline ensinar & 39 & sociedade & 7 & atividade & 2 \\
\hline oportunidade & 28 & talento & 7 & contribuir & 2 \\
\hline valor & 21 & arte & 6 & humano & 2 \\
\hline vida & 20 & conhecimento & 6 & jovens & 2 \\
\hline ajudar & 19 & projeto & 6 & mudar & 2 \\
\hline pessoa & 15 & criança & 5 & música & 2 \\
\hline cultura & 14 & Descobrir & 5 & musical & 2 \\
\hline transformar & 12 & estilo & 5 & profissionais & 2 \\
\hline bom & 10 & realização & 5 & responsabilidade & 2 \\
\hline humanismo & 9 & Interessante & 4 & & \\
\hline diversão & 7 & potencialidades & 4 & & \\
\hline
\end{tabular}

Fonte: Elaborado pelo autor, 2019.

As três primeiras palavras são conectadas à pedagogia que é necessária para o desenvolvimento de uma pessoa. É claro que, para os envolvidos no contexto social da Orquestra Jovem Recanto Maestro, a Orquestra existe para a aplicação de uma técnica, para o desenvolvimento, aprimoramento. Aprende, desenvolve, ensina, mas falta algo que seja reversível à identidade do projeto. Porque não é somente ensinar, aprender e se desenvolver em um instrumento: a novidade trazida pela Ontopsicologia e aplicada na pedagogia é a descoberta do Em Si ôntico. Na palavra realização, que aparece na definição de pedagogia colocada acima, está contido a finalidade da Ontopsicologia. A Orquestra existe com a finalidade da realização: tocar para ser.

Apresenta-se a seguir os resultados da pergunta que se fez sobre a missão da Orquestra. Qual é o entendimento que os diferentes grupos têm sobre Tocar para Ser? Nos questionários do grupo Aluno, a palavra que ocorre mais vezes é pessoa, que Meneghetti define como "unidade de ação que um sujeito representa como entidade e fenomenologia: dentro de si mesmo, como máscara social, como princípio último de egoísmo e responsabilidade" (2012, p. 211). Como segunda palavra aparece vida e, como terceira, melhor. Por exemplo, um aluno escreve que Tocar para Ser "significa que a música nos transforma em pessoas com futuros bons, transforma nossa vida em algo melhor". 
Já no grupo Pai/Mãe ou responsável a primeira palavra é melhor e a segunda, pessoa. Assim como no grupo Aluno, essas palavras ocorrem várias vezes. Interessante a frase de um Pai/Mãe ou Responsável: “Tocar para ser, para mim, significa que tanto a criança e o jovem que se envolve desde cedo com a música é mais desenvolvido tanto na vida escolar como na sociedade". Outro pesquisado expõe que "tocar para ser uma pessoa, alguém na vida".

Um dos respondentes do grupo Amigo, Padrinho/Madrinha explica que “"Tocar para ser' eu compreendo de dois modos: a música do ser do músico; e também um estímulo à dialética entre músico e fruidor. Ao tocar a música do ser que se é, essa toca o ser de outra pessoa, e a estimula a ser também o ser que é”. Já um participante do grupo Staff resume dizendo que Tocar para Ser "é viver cotidianamente o ideal musical que se quer representar. É ter no fazer musical um estilo de vida". As primeiras palavras estão relacionadas com o fazer música. Em um questionário do grupo Público em Geral encontramos que "a música me toca de tal modo a reforçar o meu ser. Também sou o que toco, o que ouço". Nessa mesma linha, um outro explica que significa "aprender, se desenvolver, para crescer como pessoa, ser um indivíduo superior”.

Na Figura 3, por meio da nuvem de palavras, expressa-se o entendimento geral dos grupos estudados com relação à missão da Orquestra Jovem Recanto Maestro.

Figura 3 - Nuvem de palavras do entendimento da missão Tocar para Ser pelos grupos: público em geral; amigo, padrinho/madrinha; pai/mãe ou responsável; aluno; staff.

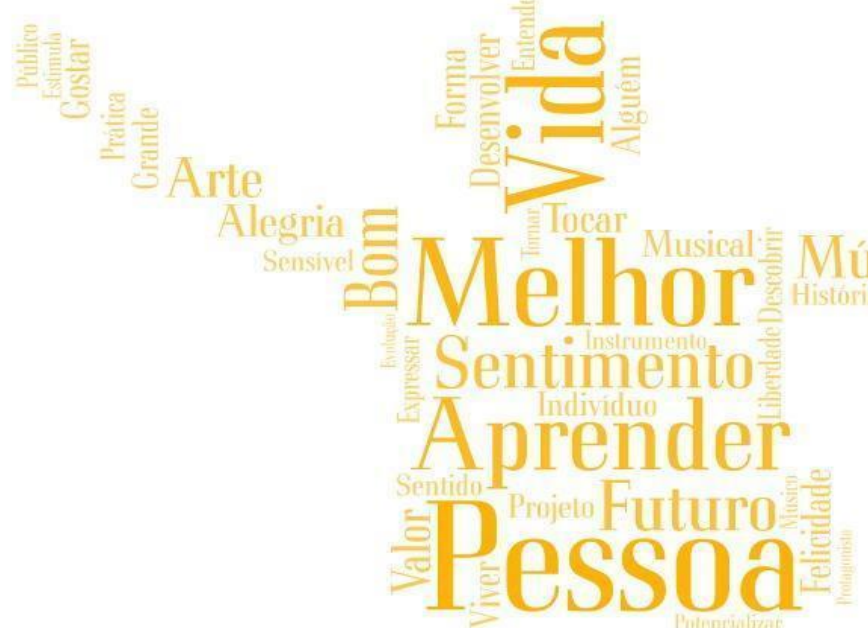

Fonte: Elaborado pelo autor, 2019. 
Quadro 3 - Visão geral do entendimento da missão Tocar para Ser pelos grupos: público em geral; amigo, padrinho/madrinha; pai/mãe ou responsável; aluno; staff.

\begin{tabular}{|c|c|c|c|c|c|}
\hline Palavra & quant. & Palavra & quant. & Palavra & quant. \\
\hline pessoa & 39 & descobrir & 6 & prática & 3 \\
\hline melhor & 37 & expressar & 6 & projeto & 3 \\
\hline vida & 36 & Arte & 4 & protagonista & 3 \\
\hline aprender & 25 & crescer & 4 & público & 3 \\
\hline bom & 20 & despertar & 4 & sensível & 3 \\
\hline sentimento & 20 & forma & 4 & unidade & 3 \\
\hline desenvolver & 14 & gostar & 4 & viver & 3 \\
\hline futuro & 14 & grande & 4 & estimula & 2 \\
\hline música & 12 & liberdade & 4 & evolução & 2 \\
\hline alguém & 9 & musical & 4 & história & 2 \\
\hline alegria & 7 & tocar & 4 & instrumento & 2 \\
\hline alma & 7 & entender & 3 & músico & 2 \\
\hline felicidade & 7 & indivíduo & 3 & sentido & 2 \\
\hline valor & 7 & potencializar & 3 & tornar & 2 \\
\hline
\end{tabular}

As palavras pessoa, melhor e vida aparecem em evidência na Figura 3, como também no Quadro 3, sendo as três palavras com mais ocorrências no entendimento geral dos grupos que participam do contexto da Orquestra sobre Tocar para Ser. Meneghetti define a palavra pessoa como: "Projeção como Eu histórico por parte do Em Si ôntico" (2012, p. 211). Poderia formular a frase que Tocar para Ser, para os diferentes grupos, significa se tornar uma pessoa melhor na vida. Percebe-se que existe uma correlação da percepção dos grupos com a missão da Orquestra já que o sujeito busca um crescimento, uma evolução na vida. $O$ ponto é que não se compreende ainda a profundidade e significado do ser para esse desenvolvimento histórico. É na história que o ser se projeta.

No que diz respeito ao outro instrumento de coleta de dados, ou seja, as entrevistas do grupo Diretoria, os participantes se depararam com a pergunta sobre o propósito da Orquestra Jovem Recanto Maestro. Um dos entrevistados fala sobre a missão da Orquestra 
e do diferencial do projeto que é o de produzir na orquestra, no público, uma experiência que revele o ser. Para outro, o propósito é usar a música para abrir horizontes, que a arte e a música sejam essenciais. Outro participante do grupo, ao falar sobre o propósito da Orquestra, cita que o projeto faz com que crianças e jovens descubram sua própria identidade, seu ponto força e que, através da responsabilidade e do protagonismo, possam fazer a diferença na sociedade. Por outro lado, outro pesquisado discute um pouco sobre o valor da excelência ao citar que o propósito da Orquestra está em formar músicos com excelência. Também afirma que o projeto está transformando a realidade da sociedade local criando pessoas mais cidadãs, elementos que também encontramos no protagonismo responsável aplicado pela pedagogia ontopsicológica em um dos valores da Orquestra Jovem Recanto Maestro. Já outro participante comenta que o propósito da Orquestra vai de acordo com o da Fundação Antonio Meneghetti e que busca a formação integral do ser humano. Para a Diretoria, o propósito da Orquestra transcende a música, o que demonstra uma correlação entre a percepção desse grupo e a identidade do projeto.

Qual a importância que esse projeto tem para o Recanto Maestro? Quando o grupo Diretoria impactou com essa pergunta citou várias vezes que a Orquestra é importante para a formação não só dos que participam diretamente dela, como também dos estudantes da Faculdade Antonio Meneghetti (AMF) e dos moradores e clientes do Recanto Maestro. Para as pessoas que estão buscando algo mais, um concerto que acontece no auditório principal da AMF, por exemplo, é a energia que se precisa.

Quando perguntado sobre os resultados que esse projeto traz para a Fundação Antonio Meneghetti, os entrevistados falam a respeito da importância da formação de acordo à Ontopsicologia e da cultura oferecida através dos concertos para a formação das pessoas que convivem com o Recanto Maestro. Interessante é destacar o entendimento de um dos entrevistados de que "mesmo que você não ensine diretamente a Ontopsicologia, você parte de princípios da ciência ontopsicológica". Outro complementa que "a Fundação tem lá no estatuto o objetivo de desenvolver projetos educacionais alinhados aos objetivos das Nações Unidas e sempre com o intuito de divulgação das descobertas da ciência ontopsicológica". A Orquestra Jovem Recanto Maestro fala, toca e ensina através da música a Tocar para Ser. 


\section{Considerações Finais}

Conclui-se este trabalho, tendo alcançado a resposta para a pergunta que se propôs investigar sobre se a percepção dos diferentes grupos que compõe o contexto social da Orquestra Jovem Recanto Maestro tem correlação com a identidade do projeto. Ao longo do texto se apresentou as especificidades da Ontopsicologia e suas aplicações na OntoArte e na Pedagogia Ontopsicológica, que definem a identidade da Orquestra. Também foi possível descrever a missão Tocar para Ser, assim como os valores de Excelência, Protagonismo Responsável e Estética como Ética em relação à Ontopsicologia. Através da pesquisa se colheu as manifestações dos grupos Diretoria, Alunos, Pai/Mãe ou Responsável, Amigo, Padrinho/Madrinha, Staff, Público em Geral.

Foi possível constatar que existe uma reversibilidade entre a percepção dos entrevistados e a identidade da Orquestra descrita nesse trabalho. Se obteve inúmeras manifestações com a palavra responsabilidade, que constitui um conceito base da pedagogia ontopsicológica e que está presente nos valores da Orquestra. Esse ponto se evidenciou em várias manifestações nos questionários e entrevistas. Também se encontrou uma correlação com a identidade do projeto no que diz respeito à palavra alegria. O critério da Ontopsicologia é o Em Si ôntico e esse é percebido através de suas 15 fenomenologias e dentre elas está presente o ser alegre. Outro ponto de correlação foi a palavra pessoa, usada para explicar a missão da Orquestra: deve haver uma busca pelo crescimento de cada um dos envolvidos, para ser pessoa. O grupo Diretoria manifestou de diferentes formas nas entrevistas que o Projeto Orquestra Jovem Recanto Maestro é um instrumento para que a Ontopsicologia possa tocar e transformar o ser humano e seu contexto.

Com o intuito de fortalecer as ações do projeto Orquestra Jovem Recanto Maestro, com base em sua identidade, é necessário observar que muito pouco se mostrou na pesquisa a correlação entre as percepções dos grupos Aluno, Pai/Mãe ou Responsável e Staff com os conceitos apresentados da OntoArte. Isso poderia ser trabalhado em grupos de estudos teóricos e práticos, para que esses grupos que compõem o contexto social da Orquestra tenham um melhor entendimento e uma vivência prática sobre o tema. É importante se investir na excelente formação técnica, mas não pode ser vista como um fim em si mesma, e sim um meio que se utiliza para alcançar a Arte do ser. 


\section{Referências}

ABBAGNANO, Nicola. Dicionário de Filosofia. São Paulo: Martins Fontes Editora, 2007.

AMARAL, Fernando. Introdução à ciência de dados: mineração de dados e big data. Rio de Janeiro: Alta Books, 2016.

ASSOCIAÇÃO BRASILEIRA DE ONTOPSICOLOGIA. Cultura \& Educação: uma nova pedagogia para a sociedade futura. Recanto Maestro, Restinga Sêca, RS: Ontopsicológica Editora Universitária, 2015.

CAROTENUTO, Margherita. Histórico sobre as teorias do conhecimento. São João do Polêsine, RS: Ontopsicológica Editrice, 2009.

CARRARA, Cláudio. In: SYMPOSIUM INTERNACIONAL "PEDAGOGIA CONTEMPORÂNEA: RESPONSABILIDADE E FORMAÇÃO DO JOVEM PARA A SOCIEDADE DO FUTURO. 2017. UNESCO. Paris. 1 vídeo (87 min).

CELIBIDACHE, Man will nichts - man läßt es entstehen. Direção: Jan Schmidt-Garre. 1992. 1 vídeo (100 min). Disponível em: https://www.youtube.com/watch?v=4nzHHzS9Lk. Acesso em: 29 jun. 2020.

EL SISTEMA. Uma obra de 41 años en la palabra de um artista visionário. 2016. 1 vídeo (26 min). Publicado pelo canal El Sistema. Disponível em: https://www.youtube.com/watch?v=9GvygLTLIpA. Acesso em: 29 jun. 2020.

FONTERRADA, Marisa Trench de Oliveira. De tramas e fios: um ensaio sobre música e educação. São Paulo: Editora UNESP; Rio de Janeiro: Funarte, 2008.

FUNDAÇÃO ANTONIO MENEGHETTI. Posicionamento Institucional. Anais II Cong. Int. Uma Nova Pedagogia para a Sociedade Futura, 2016. https://reciprocidade.emnuvens.com.br/novapedagogia/article/view/132/153. Acesso em: 26 jul. 2020.

GOMES, Carlos Alberto Faísca Fernandes. Discursos sobre a "Especificidade" do Ensino Artístico: A sua Representação Histórica nos Séculos XIX e XX. 2002. Tese (Mestrado em Ciências da Educação) - Faculdade de Psicologia e Ciências da Educação, Universidade de Lisboa. 2002. Disponível em: https://repositorio.ul.pt/handle/10451/34811. Acesso em: 05 jul. 2020.

LOVATO, Gustavo. Aplicação da Mineração de Textos na Análise de Produções Textuais. 2015. Trabalho de Conclusão de Curso (Bacharelado em Ciência da Computação) - Centro de Ciências Exatas e da Tecnologia, Universidade de Caxias do Sul. 2015. Disponível em: https://repositorio.ucs.br/xmlui/bitstream/handle/11338/1516/TCC\%20Gustavo\%20Lovato .pdf? sequence $=1 \&$ isAllowed=y. Acesso em: 29 jun. 2020.

MENEGHETTI, Antonio. OntoArte: O Em Si da Arte. Florianópolis: Ontopsicológica Editrice, 2003. 
MENEGHETTI, Antonio. Manual de Ontopsicologia. Recanto Maestro: Ontopsicológica Editora Universitária, 2010.

MENEGHETTI, Antonio. Dicionário de Ontopsicologia. Recanto Maestro: Ontopsicológica Editora Universitária, 2012.

MENEGHETTI, Antonio. Pedagogia Ontopsicológica. Recanto Maestro: Ontopsicológica Editora Universitária, 2014.

MENEGHETTI, Antonio. Antonio Meneghetti sobre: Jovens e realidade cotidiana. Recanto Maestro, São João do Polêsine, RS: Fundação Antonio Meneghetti, 2017.

MENEGHETTI, Antonio. Antonio Meneghetti sobre... Criatividade e sensibilidade estética. Recanto Maestro, São João do Polêsine, RS: Fundação Antonio Meneghetti, 2018.

ROCA, Juan Antonio Gallastegui. Fenomenologia de la música de Serguiu Celibidache y su influencia em la dirección de orquestra en España. 2017. Tese (Doutorado em Ciências Humanas e Sociais) - Faculdade de Letras e da Educação, Universidad de la Rioja, Espanha, 2017. Disponível em: https://dialnet.unirioja.es/descarga/tesis/121203.pdf. Acesso em: 29 jun. 2020.

STAUDT, Jorge Luiz Junior. Text Mining utilizando o Software R: um estudo de caso de uma biblioteca americana. 2016. Trabalho de Conclusão de Curso (Bacharel em Estatística) - Instituto de Matemática, Departamento de Estatística, Universidade Federal do Rio Grande do Sul. 2016.2 Disponível em: https://www.lume.ufrgs.br/bitstream/handle/10183/149102/001004730.pdf?sequence=1. Acesso em: 29 jun. 2020. 